\title{
The prognosis for prognosis remains excellent
}

\author{
Christopher L. Hansen, MD, FASNC
}

\section{See related article, pp. 519-528}

Do we really need another paper on prognosis? The topic has been explored exhaustively. We have seen studies identifying the ability of myocardial perfusion imaging (MPI) to stratify prognosis with planar imaging and SPECT, thallium, sestamibi, tetrofosmin, dual isotope, and rubidium. ${ }^{1-11} \mathrm{We}$ have heard about prognosis using treadmill exercise and pharmacologic stress using dipyridamole, adenosine, and dobutamine..$^{5,10,12-15} \mathrm{We}$ have read studies looking at men, women, metabolic syndrome, obesity, diabetics, and patients with endstage renal disease. ${ }^{5,16-20}$ The literature is peppered with studies looking at low and intermediate Duke treadmill scores, patients with LBBB, left ventricular hypertrophy, and normal EKGs. ${ }^{12,21-23}$ There are papers looking at patients with suspected coronary disease, catheterization documented coronary disease, stable angina, and post infarction patients. ${ }^{10,13,24,25}$ When it seems that the list is complete, when every conceivable subgroup has been identified and studied, Doukky et $\mathrm{al}^{26}$ have managed to identify yet another group: MPI in an outpatient primary care setting. As a group, this referral population would be expected to have less acuity and presumably a better prognosis, but as this group is more reflective of the general population it certainly merits careful scrutiny.

They identified a consecutive series of 1,546 patients of whom greater than 1400 met entry criteria; a mean follow-up of 27 months was obtained in $99 \%$. The majority of the scans were normal, only $12.5 \%$ were deemed abnormal due to perfusion defects, decreased function or both. Not surprisingly, the overall cardiac event rates were both hard events (mortality and myocardial infarction) and revascularization were low. Cox analysis once again showed that an abnormal MPI was a

From the Thomas Jefferson University, Philadelphia, PA.

Reprint requests: Christopher L. Hansen, MD, FASNC, Thomas Jefferson University, Philadelphia, PA, USA; christopher.hansen @jefferson.edu.

J Nucl Cardiol 2013;20:501-3.

1071-3581/\$34.00

Copyright (C) 2013 American Society of Nuclear Cardiology.

doi:10.1007/s12350-013-9703-5 strong predictor of cardiac events while the overall event rates in patients with normal scans was quite low $(0.54 \%$ death or MI) somewhat lower than the approximately $1 \%$ rate reported in cardiologist-based practices. The summed stress score, as in previous studies, showed a stepwise influence on prognosis.

The study was performed using only a single blinded reader using semi-quantitative analysis with commercially available software. It should be noted that the authors used a SSS of $\geq 1$ as abnormal, a deviation from most of the published literature. This is unlikely to effect the conclusions as the most important finding is the correlation between SSS and outcome and not where the line between normal and abnormal is drawn.

This study raises important questions about appropriateness. This includes not just whether the indication for the test was appropriate but also the appropriate follow-up of abnormal tests and the appropriateness of the appropriate use criteria themselves. The authors report that nearly half the studies ordered were classified as inappropriate under the current AUC criteria. It is noted that AUC criteria were not as widely recognized during the time the study was conducted; it would not be surprising if the clinical practice of the ordering physicians has changed since then reflecting better recognition and adoption of these criteria. It is also likely that primary care physicians will be slower to incorporate the AUC guidelines than cardiologists.

The appropriateness of evaluation of patients with abnormal scans is perhaps a greater concern. Less than half of the patients with significantly abnormal MPI underwent catheterization and only one-third were revascularized. The authors suggest that this reflects inappropriate patient selection but could also reflect poor understanding of the clinical implications of a significantly abnormal study in a primary care setting. Presumably, once a patient makes it to the catheterization laboratory, clinical decisions will be strongly influenced by cardiologists. One is much less certain about the other half that were not catheterized and whether this high risk group received optimal care.

Finally, this study raises questions about the appropriate use criteria themselves. It is not surprising that patients meeting AUC criteria had a higher percentage of abnormal MPI (13.3\% vs 6.9\%), which reflects the AUC's criteria for identifying higher risk patients. The concern is the relatively high rate of 
positive scans in the inappropriate group. Of course, the simple finding of a positive scan does not invalidate the AUC; outcomes data would be needed to definitively answer this question. But the positive scan rate of nearly $7 \%$ in a presumably low risk group should give us pause. We are all witnessing the bureaucratization of clinical decision making borne of desire to reduce costs and mistrust of physician motivations when ordering tests. Challenging clinical judgement, without clear understanding of its implications on patient outcome can have dire consequences; this study only adds to these concerns. Clearly, further study is needed.

This paper joins the now very long list of studies that have consistently shown the ability of MPI to assess prognosis in virtually every subgroup studied and reinforces the superiority of physiology over anatomy when it comes to evaluating patients with coronary disease. The preeminence of physiology as the arbitrator of the optimal treatment of a patient with stable angina pectoris has lately gained overwhelming support from a totally different venue. Investigators using fractional flow reserve in the FAME I-II and DEFER trials convincingly demonstrated that the physiologic effect of a coronary stenosis is the most important factor in identifying patients most likely to benefit from revascularization. ${ }^{27-29}$

Prognosis is the past, present, and future of nuclear cardiology. So, yes, another paper on prognosis is welcome.

\section{References}

1. Ladenheim ML, Pollock BH, Rozanski A, et al. Extent and severity of myocardial hypoperfusion as predictors of prognosis in patients with suspected coronary artery disease. J Am Coll Cardiol 1986;7:464-71.

2. Gill JB, Ruddy TD, Newell JB, Finkelstein DM, Strauss HW, Boucher CA. Prognostic importance of thallium uptake by the lungs during exercise in coronary artery disease. N Engl J Med 1987;317:1486-9.

3. Kaul S, Finkelstein DM, Homma S, Leavitt M, Okada RD, Boucher CA. Superiority of quantitative exercise thallium-201 variables in determining long-term prognosis in ambulatory patients with chest pain: A comparison with cardiac catheterization. J Am Coll Cardiol 1988;12:25-34.

4. Berman DS, Hachamovitch R, Kiat H, et al. Incremental value of prognostic testing in patients with known or suspected ischemic heart disease: A basis for optimal utilization of exercise technetium-99m sestamibi myocardial perfusion single-photon emission computed tomography. J Am Coll Cardiol 1995;26:639-47.

5. Hachamovitch R, Berman DS, Kiat H, et al. Effective risk stratification using exercise myocardial perfusion SPECT in women: Gender-related differences in prognostic nuclear testing. J Am Coll Cardiol 1996;28:34-44.

6. Iskander S, Iskandrian AE. Risk assessment using single-photon emission computed tomographic technetium-99m sestamibi imaging. J Am Coll Cardiol 1998;32:57-62.
7. Hachamovitch R, Berman DS, Kiat H, Cohen I, Friedman JD, Shaw LJ. Value of stress myocardial perfusion single photon emission computed tomography in patients with normal resting electrocardiograms: An evaluation of incremental prognostic value and cost-effectiveness. Circulation 2002;105:823-9.

8. Marwick TH, Shan K, Patel S, Go RT, Lauer MS. Incremental value of rubidium-82 positron emission tomography for prognostic assessment of known or suspected coronary artery disease. Am J Cardiol 1997;80:865-70.

9. Yoshinaga $\mathrm{K}$, Chow BJ, Williams $\mathrm{K}$, et al. What is the prognostic value of myocardial perfusion imaging using rubidium-82 positron emission tomography? J Am Coll Cardiol 2006;48:1029-39.

10. Elhendy A, Schinkel AF, van Domburg RT, et al. Risk stratification of patients with angina pectoris by stress $99 \mathrm{mTc}-$ tetrofosmin myocardial perfusion imaging. J Nucl Med 2005;46: 2003-8.

11. Dorbala S, Di Carli MF, Beanlands RS, et al. Prognostic value of stress myocardial perfusion positron emission tomography: Results from a multicenter observational registry. J Am Coll Cardiol 2013;61:176-84.

12. Hachamovitch R, Berman DS, Kiat H, et al. Exercise myocardial perfusion SPECT in patients without known coronary artery disease: Incremental prognostic value and use in risk stratification. Circulation 1996;93:905-14.

13. Machecourt J, Longere P, Fagret D, et al. Prognostic value of thallium-201 single-photon emission computed tomographic myocardial perfusion imaging according to extent of myocardial defect. Study in 1,926 patients with follow-up at 33 months. J Am Coll Cardiol 1994;23:1096-106.

14. Hachamovitch R, Berman DS, Shaw LJ, et al. Incremental prognostic value of myocardial perfusion single photon emission computed tomography for the prediction of cardiac death: Differential stratification for risk of cardiac death and myocardial infarction. Circulation 1998;97:535-43.

15. Berman DS, Kang X, Hayes SW, et al. Adenosine myocardial perfusion single-photon emission computed tomography in women compared with men. Impact of diabetes mellitus on incremental prognostic value and effect on patient management. J Am Coll Cardiol 2003;41:1125-33.

16. Giri S, Shaw LJ, Murthy DR, et al. Impact of diabetes on the risk stratification using stress single-photon emission computed tomography myocardial perfusion imaging in patients with symptoms suggestive of coronary artery disease. Circulation 2002;105:32-40.

17. Shaw LJ, Berman DS, Hendel RC, et al. Cardiovascular disease risk stratification with stress single-photon emission computed tomography technetium- $99 \mathrm{~m}$ tetrofosmin imaging in patients with the metabolic syndrome and diabetes mellitus. Am J Cardiol 2006; $97: 1538-44$

18. Kim JK, Kim SG, Kim HJ, Song YR. Cardiac risk assessment by gated single-photon emission computed tomography in asymptomatic end-stage renal disease patients at the start of dialysis. J Nucl Cardiol 2012;19:438-47.

19. Elhendy A, Schinkel AF, van Domburg RT, et al. Prognostic stratification of obese patients by stress $99 \mathrm{mTc}$-tetrofosmin myocardial perfusion imaging. J Nucl Med 2006;47:1302-6.

20. Duvall WL, Croft LB, Corriel JS, et al. SPECT myocardial perfusion imaging in morbidly obese patients: Image quality, hemodynamic response to pharmacologic stress, and diagnostic and prognostic value. J Nucl Cardiol 2006;13:202-9.

21. Gibbons RJ, Hodge DO, Berman DS, et al. Long-term outcome of patients with intermediate-risk exercise electrocardiograms who do not have myocardial perfusion defects on radionuclide imaging. Circulation 1999;100:2140-5. 
22. America YG, Bax JJ, Boersma E, Stokkel M, van der Wall EE. Prognostic value of gated SPECT in patients with left bundle branch block. J Nucl Cardiol 2007;14:75-81.

23. Elhendy A, Schinkel AF, van Domburg RT, et al. Prognostic implications of stress Tc-99m tetrofosmin myocardial perfusion imaging in patients with left ventricular hypertrophy. J Nucl Cardiol 2007;14:550-4.

24. Brown KA. Prognostic value of myocardial perfusion imaging: State of the art and new developments. J Nucl Cardiol 1996;3: 516-37.

25. Leppo JA, O'Brien J, Rothendler JA, Getchell JD, Lee VW. Dipyridamole-thallium-201 scintigraphy in the prediction of future cardiac events after acute myocardial infarction. N Engl J Med 1984;310:1014-8.

26. Doukky R, Frogge N, Balakrishnan G, et al. The prognostic value of cardiac SPECT performed at the primary care physician's office. J Nucl Cardiol 2013. doi:10.1007/s12350-013-9676-4.
27. Pijls NH, Fearon WF, Tonino PA, et al. Fractional flow reserve versus angiography for guiding percutaneous coronary intervention in patients with multivessel coronary artery disease: 2-Year follow-up of the FAME (fractional flow reserve versus angiography for multivessel evaluation) study. J Am Coll Cardiol 2010;56:177-84.

28. Pijls NH, van Schaardenburgh P, Manoharan G, et al. Percutaneous coronary intervention of functionally nonsignificant stenosis: 5-Year follow-up of the DEFER study. J Am Coll Cardiol 2007;49:2105-11.

29. De Bruyne B, Pijls NH, Kalesan B, et al. Fractional flow reserveguided PCI versus medical therapy in stable coronary disease. N Engl J Med 2012;367:991-1001. 